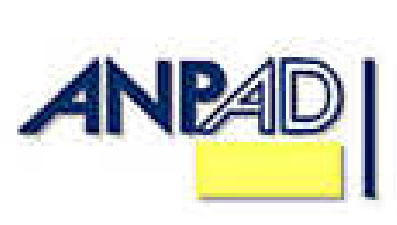

Disponível em

http://www.anpad.org.br/rac

RAC, Curitiba, v. 15 , n. 6 , art. 1 ,

pp. 973-992, Nov./Dez. 2011

$\left(\right.$ (c) EY-NG $^{-N}$

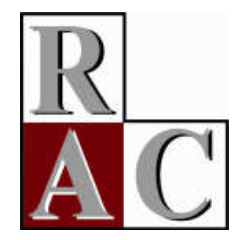

\title{
Comprometimento e Entrincheiramento na Carreira: um Estudo de suas Influências no Esforço Instrucional do Docente do Ensino Superior
}

\section{Commitment and Entrenchment in a Career: a Study of Their Influences on the Institutional Effort of Higher Education Teachers}

\author{
Diva Ester Okazaki Rowe * \\ E-mail: divarowe@gmail.com \\ Universidade Federal da Bahia - NPGA/UFBA \\ Salvador, BA, Brasil. \\ Antonio Virgílio Bittencourt Bastos \\ E-mail: virgilio@ufba.br \\ Universidade Federal da Bahia - ISP/NPGA/UFBA \\ Salvador, BA, Brasil. \\ Ana Paula Moreno Pinho \\ E-mail: anamorenopinho@gmail.com \\ Faculdades Unime \\ Salvador, BA, Brasil.
}

* Endereço: Diva Ester Okazaki Rowe

Escola de Administração, NPGA/UFBA, Av. Reitor Miguel Calmon, s/n., Vale do Canela, Salvador/BA, 40110-903.

Copyright (C) 2011 RAC. Todos os direitos, até mesmo de tradução, são reservados. É permitido citar parte de artigos sem autorização prévia, desde que seja identificada a fonte. 


\title{
Resumo
}

O presente trabalho analisa os vínculos de comprometimento e de entrincheiramento com a carreira, desenvolvidos por professores universitários, inseridos em instituições públicas e privadas. Mais precisamente, busca identificar as relações desses vínculos com o esforço instrucional, definido como o empenho em qualificar a atividade de ensino e potenciar os resultados positivos dos discentes. A pesquisa, extensiva e de corte transversal, abrangeu 635 docentes de diferentes Estados e envolveu a aplicação de um questionário on line. Os dados foram submetidos a análises descritivas e multivariadas, por meio do Statistical Package for Social Sciences (SPSS), versão 15.0. Após a análise exploratória (avaliação da normalidade, outliers, análise de linearidade e análise de multicolinearidade), foi realizada a análise da qualidade da mensuração das escalas (dimensionalidade, confiabilidade e validade das medidas) e, em seguida, houve a modelagem de equações estruturais, para identificar os impactos dos vínculos com a carreira sobre o esforço instrucional. O modelo com melhor ajuste revelou que a identidade (dimensão do comprometimento com a carreira) exerce impacto sobre o esforço instrucional em todas as suas dimensões. Foram encontradas também diferenças significativas entre IES públicas e privadas.

Palavras-chave: vínculos com a carreira; entrincheiramento na carreira; comprometimento com a carreira; docente do ensino superior; desempenho do docente.

\begin{abstract}
The present study analyzes the dimensions of the links of commitment and entrenchment with the career development of higher education teachers in the private and public contexts of Brazilian universities. More specifically, an attempt is made to identify their relations with the institutional effort' construct, defined as persistent improvement of quality in their performance and the positive results of the educational process. The extensive and cross-sectional study involved a sample of 635 higher education teachers from different states through an applied questionnaire and on-line data collection. The data underwent descriptive analysis as well as multivariate analysis, using the Statistical Package Social Sciences (SPSS) version 15.0. After the exploratory analysis (evaluation of normality, outliers, analysis of linearity and analysis of multicolinearity), a quality analysis was conducted of the quality of the measurement of scales (dimensionality, trustworthiness and validity of the measures), followed by the modeling of structural equations to identify the impacts of the links with the career on the institutional effort. The model, with better adjustment, revealed that identity (dimension of commitment to career) makes an impact on the institutional effort in all its dimensions. Significant differences between public and private institutions of higher education were also found.
\end{abstract}

Key words: career links; career entrenchment; career commitment; higher education teaching staff; performance of higher education teachers. 


\section{Introdução}

No campo de estudo sobre carreiras, o construto 'Entrincheiramento na Carreira', proposto por Carson, Carson e Bedeian (1995) tem sido justificado em função das mudanças econômicas constantes, acirramento da competitividade e instabilidade que induzem o desenvolvimento de novas arquiteturas organizacionais e alterações no mercado de trabalho, impactando a oferta de empregos e as condições de ascensão profissional. Diante das dificuldades associadas à empregabilidade e a esta instabilidade do mercado, é possível que a permanência numa carreira seja mais determinada pela insegurança associada à construção de novas alternativas do que propriamente de uma forte identificação e forte vínculo afetivo com a carreira já construída. A noção de entrincheiramento veio a preencher esta lacuna no campo de estudos sobre os vínculos do trabalhador com o seu trabalho, ocupação, profissão ou carreira.

A noção de estar entrincheirado pode, assim, incluir o desejo de evitar estigma social, medo de que a idade seja o limite para uma boa recolocação, medo de perder privilégios já adquiridos ou de arriscá-los com a possibilidade da adesão ao novo curso de ação. O conceito de entrincheiramento busca delimitar um tipo de vínculo que se diferencia fortemente daquele mais classicamente estudado, isto é, o comprometimento com a carreira. Este vínculo que pressupõe forte identificação com a carreira escolhida, associada a afetos positivos, constituiria outro conjunto de determinantes para a permanência e os investimentos que o trabalhador faria na construção de sua carreira. Estamos, deste modo, diante de dois construtos - entrincheiramento e comprometimento - que se reportam a atitudes em face das carreiras e que têm o potencial de gerar comportamentos muito distintos, com impactos pessoais, organizacionais e sociais expressivos.

$\mathrm{Na}$ origem desta pesquisa está o desejo de preencher algumas lacunas de estudos sobre vínculos com a carreira, mencionadas por autores nacionais e internacionais, como a necessidade de aumentar o número de pesquisas, avaliando e comparando os dois construtos, de estabelecer a relação com o desempenho e de identificar com mais precisão os consequentes dos dois construtos (Blau, 2001; Carson, Carson, Roe, \& Phillips, 1996; Lee, Carswell, \& Allen, 2000; Scheible, Bastos, \& Rodrigues, 2007).

Esta investigação tomou como unidade de análise o docente do ensino superior, por ser uma categoria que sofre os reflexos das mudanças do mundo do trabalho, podendo ser ressaltado que muitos docentes atuam em precárias condições e contratos de trabalho. E mesmo passando por situações adversas, se fazem relevantes para a sociedade contemporânea, com a sua atuação na geração e disseminação do conhecimento, que impulsiona o desenvolvimento socioeconômico e cultural do país. Essas peculiaridades desafiam o estudo dos possíveis impactos dos vínculos com a carreira no desempenho do docente.

As organizações dependem do desempenho de cada trabalhador para atingir seus objetivos; portanto a sua otimização se faz necessária. O desempenho do trabalhador resulta, dentre outros fatores, de seu esforço e de sua persistência na consolidação do mesmo.

A literatura de desempenho, como, por exemplo, Sonnentag e Frese (2002), aponta duas vertentes teóricas de análise: uma que investiga o aspecto comportamental relacionado ao desempenho, enquanto a outra investiga o resultado ou produto do desempenho. Para o presente estudo, foi delimitado o aspecto comportamental do desempenho do docente, referente ao seu esforço instrucional. A escolha desse indicador de desempenho se justifica por ser o 'ensino' um objetivo comum a todas as IES.

Apoiado nas considerações anteriores, delineia-se como problema desta pesquisa: Como os vínculos com a carreira impactam o esforço instrucional dos docentes do ensino superior? Para tanto, o trabalho almeja analisar as dimensões dos vínculos com a carreira - entrincheiramento e comprometimento, que explicam o esforço instrucional do docente, comparando os contextos público e privado do ensino superior brasileiro. A expectativa é de que esses contextos se diferenciem 
fortemente no tocante às condições oferecidas ao docente do ensino superior no tocante à sua carreira. Enquanto as instituições públicas fornecem estabilidade e oportunidades de qualificação continuada, no setor privado não há estabilidade para o trabalho dos seus docentes.

Para atingir o objetivo proposto neste artigo, faz-se uma apresentação geral da literatura sobre o vínculo com a carreira, contemplando os dois construtos centrais. Em seguida, descrevem-se as decisões metodológicas envolvidas na construção da pesquisa empírica. A parte seguinte explora e discute os resultados obtidos, relatando o material coletado entre os sujeitos que participaram da pesquisa e que representam a categoria docente do ensino superior abrangendo o território brasileiro, de IES públicas e privadas. Com base neste material, propõem-se as conclusões finais do trabalho.

\section{Vínculos com a Carreira: Comprometimento e Entrincheiramento}

O cenário socioeconômico contemporâneo influencia tanto organizações quanto indivíduos, resultando em impactos nos relacionamentos destes atores, no próprio aspecto da construção de carreiras. Desta forma, os indivíduos dificilmente conseguem sustentação para o desenvolvimento de suas carreiras em uma única organização (Nussbaum, 1991 como citado em Carson \& Bedeian, 1994). Segundo Kilimnik, Castilho e Sant'Anna (2006), estas mudanças pelas quais passam os profissionais, podem ser interpretadas como mero mecanismo de defesa, acionado pelas inconstâncias e ameaças do ambiente. Em face desta realidade, de mercado de trabalho instável e inseguro, os vínculos com a carreira adquirem relevância, principalmente pelo fato de que a carreira representa o principal foco na vida de muitas pessoas (Cohen, 2003; Lee et al., 2000).

A título de fundamentação teórica, este segmento está dividido em duas partes, iniciando com uma visão geral de comprometimento com a carreira, seguida pela seção que aborda o entrincheiramento na carreira, que são os vínculos com a carreira sob análise neste estudo.

\section{Conceito e dimensões do comprometimento com a carreira}

Entre os vários aspectos do mundo do trabalho que podem ser alvos de um vínculo de comprometimento por parte do trabalhador, certamente a organização é o que tem merecido maior atenção por parte dos pesquisadores. Até meados dos anos 1990, a investigação do comprometimento com a carreira era um dos menos desenvolvidos (Aryee \& Tan, 1992; Bastos, 1994; Carson \& Carson, 1997). As mudanças aceleradas no mundo do trabalho e suas implicações para as trajetórias ocupacionais dos trabalhadores, alterando profundamente o próprio conceito de carreira, fizeram com que esta dimensão da vida no trabalho passasse a receber maior atenção no campo dos estudos sobre comprometimento.

Lee, Carswell e Allen (2000, p. 800) conceituam o comprometimento com a carreira como "o link psicológico entre um trabalhador e sua carreira, que é baseada na reação afetiva deste trabalhador para com a sua carreira". Este vínculo afetivo associa-se, como aponta Bastos (1994), as linhas consistentes de ação que permitem a construção de um sentido de trajetória e crescimento num campo ocupacional, quer dentro de uma organização específica, quer envolvendo diversas organizações e mesmo ocupações. O comprometimento com a carreira, assim entendido, é fortemente decorrente dos processos de sua escolha e dos processos que cercam o seu ingresso.

O comprometimento com a carreira envolve o desenvolvimento de objetivos de carreira, que pode acontecer ao longo de diversos empregos através da vida profissional do trabalhador. Como também envolve a identificação do trabalhador com sua carreira, assim como a expressão de seus valores profissionais e vocacionais. Portanto, um trabalhador que empregue energia e persista em seus objetivos pessoais de carreira poderá ser considerado possuidor de alto nível de comprometimento (Goulet \& Singh, 2002). 
Inicialmente, a pesquisa do comprometimento com a carreira foi fortemente dominada pelo modelo unidimensional, concebido por Blau (1985), que propôs uma escala de sete itens, utilizada nos primeiros estudos no Brasil (Bastos, 1994). Nos anos 1990 surge um modelo multidimensional, proposto por Carson e Bedeian (1994), que teve sua origem no modelo de London (1983). Nesse modelo, a mensuração do construto comprometimento com a carreira utiliza uma escala de três fatores e 12 itens, proposta pelos mesmos pesquisadores. A escala possui três sub-escalas, com quatro itens cada uma, que mensuram fatores de identidade, resiliência e planejamento de carreira, que se encontram descritos na Figura 1:

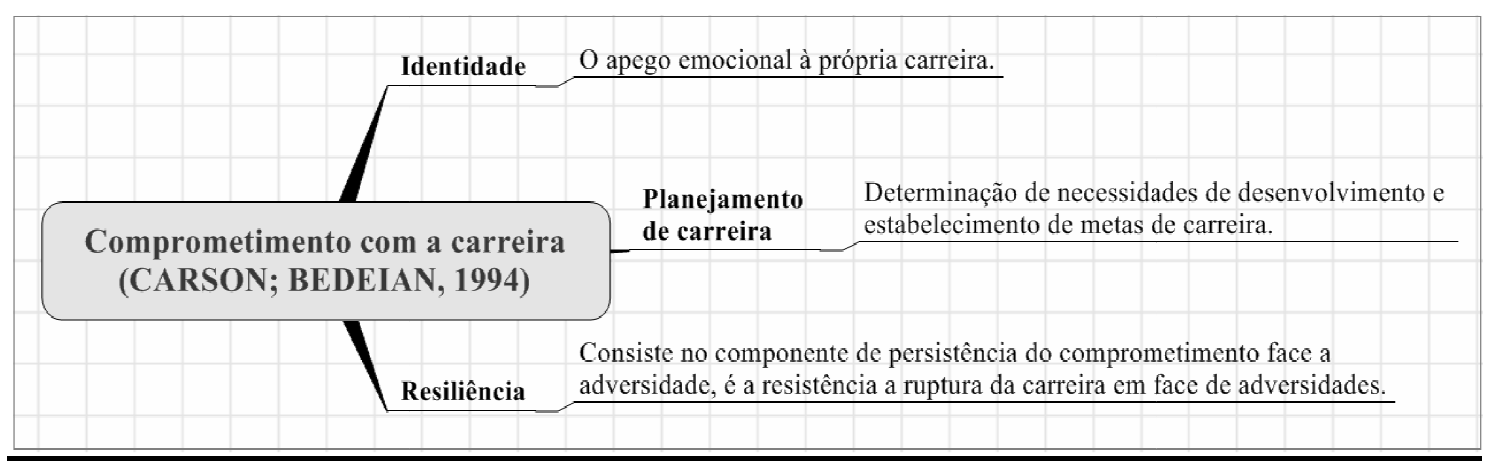

Figura 1. As Dimensões do Comprometimento com a Carreira.

Fonte: Elaborado pelos autores a partir de Carson, K., \& Bedeian, A. (1994). Career commitment: construction of a measure and examination of its psychometric properties (pp. 238-241, pp. 251-253). Journal of Vocational Behavior, 44(3), 237-262. doi: 10.1006/jvbe.1994.

O comprometimento com a carreira é importante vínculo no conjunto de vínculos que o indivíduo desenvolve no seu contexto de trabalho e se torna indispensável em um mundo de trabalho que requer, cada vez mais, o autogerenciamento do próprio desempenho, a partir de metas e objetivos que articulam demandas organizacionais e necessidades ou expectativas pessoais. Como afirmam Somech e Bogler (2002), diferentes profissionais têm de tomar decisões rápidas que não podem ser supervisionadas facilmente por terceiros, e seus clientes não têm conhecimento suficiente para avaliar o serviço recebido. Assim, a qualidade do seu desempenho pode ser fortemente impactada pelo nível em que se identifica com a sua carreira e a planeja de forma a aprimorar continuamente seu desempenho. Este é o caso, também, dos docentes, cujo desempenho deve ser, em grande parte, automonitorado, pelas dificuldades ou mesmo impropriedade de que os gestores educacionais possam observar docentes, avaliar sua performance e suas práticas específicas; portanto um docente comprometido com sua carreira pode ser crucial para se obter um ensino de qualidade.

\section{Entrincheiramento na carreira: conceito, dimensões e suas relações com o comprometimento}

O conceito de entrincheiramento na carreira proposto por Carson et al. (1995) consiste na ligação do trabalhador com a carreira, em função dos investimentos já feitos, bem como dos preços emocionais a serem pagos em caso de mudança, e à falta de caminhos profissionais alternativos. Para os autores, trata-se de um construto multidimensional com três componentes: (a) investimentos na carreira; (b) custos emocionais; e (c) falta de alternativas de carreira, descritos na Figura 2: 


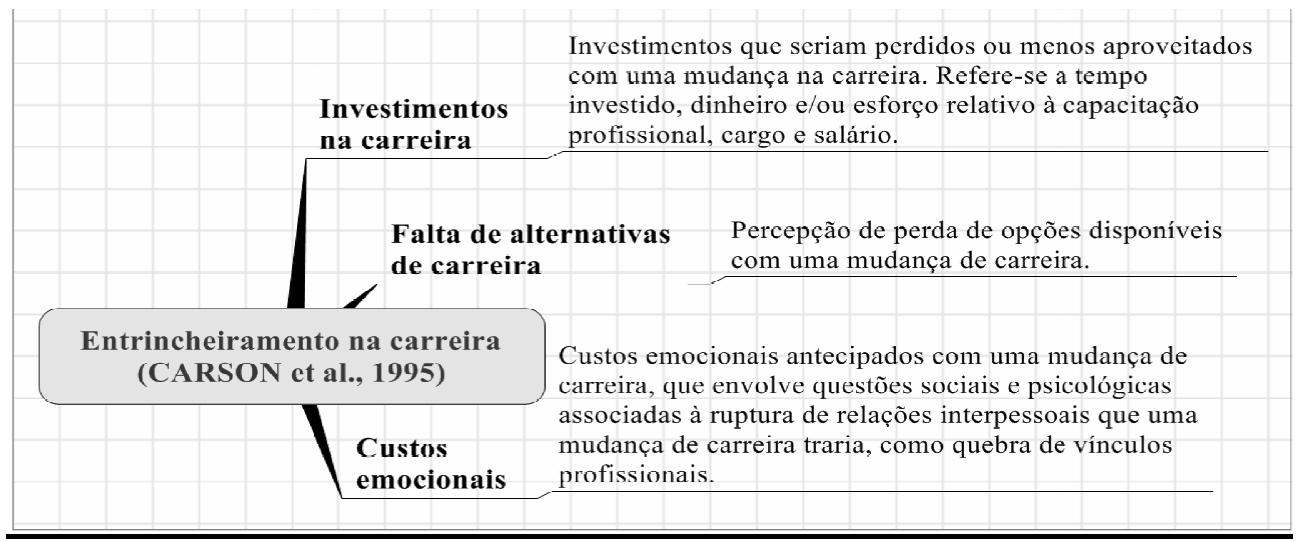

Figura 2. As Dimensões do Entrincheiramento na Carreira.

Fonte: Elaborado pelos autores a partir de Carson, K., Carson, P., \& Bedeian, A. (1995). Development and construct validation of a career entrenchment measure (pp. 303-304, pp. 310-311). Journal of Occupational and Organizational Psychology, 68(4), 301-320. doi: 10.1111/j.2044-8325.1995.tb00589.x

Para Carson, Carson, Roe e Phillips (1996), estar entrincheirado na carreira não implica necessariamente estar insatisfeito. A Figura 3 sintetiza a matriz que associa esses dois conceitos. Podese visualizar que se os trabalhadores forem, ambos, entrincheirados na carreira e insatisfeitos com a carreira, se tornam aprisionados a sua carreira (Strube, 1988 como citado em Carson et al., 1996). Alguns podem estar satisfeitos com seu entrincheiramento, porque, embora sejam limitadas as suas escolhas da carreira, podem ser satisfeitos com seu desenvolvimento, segundo Bretz e Judge (1994 como citado em Carson et al., 1996).

\begin{tabular}{|c|c|c|}
\hline \multirow{2}{*}{ A } & \multicolumn{2}{|c|}{ Satisfação na carreira } \\
\hline & Baixo & Alto \\
\hline \multirow{2}{*}{$\begin{array}{l}\text { Entrincheiramento na } \\
\text { carreira }\end{array}$} & $\begin{array}{l}\text { Aprisionado } \\
\text { Nível elevado de comprometimento } \\
\text { organizacional instrumental. } \\
\text { Baixa intenção de deixar a carreira. } \\
\text { Longo tempo no cargo/carreira. }\end{array}$ & \begin{tabular}{l}
\multicolumn{1}{c}{ Satisfeito imóvel } \\
O mais alto nível de comprometimento \\
com a carreira. \\
Alto nível de comprometimento \\
organizacional afetivo. \\
Nível elevado de comprometimento \\
organizacional instrumental. \\
Longo tempo no cargo/carreira. \\
Maior experiência educacional. \\
Baixa intenção de deixar a carreira.
\end{tabular} \\
\hline & $\begin{array}{l}\quad \text { Trocar de carreira } \\
\text { O mais alto nível de intenção de deixar } \\
\text { a carreira. } \\
\text { O nível mais baixo de } \\
\text { comprometimento com a carreira. } \\
\text { O menor tempo na carreira. } \\
\text { A menor experiência educacional. }\end{array}$ & \begin{tabular}{l}
\multicolumn{1}{c}{$\begin{array}{c}\text { Carreira voluntária/ } \\
\text { Voluntário }\end{array}$} \\
Alto nível de comprometimento com a \\
carreira e organizacional afetivo. \\
Longo tempo no cargo/carreira. \\
Maior experiência educacional.
\end{tabular} \\
\hline
\end{tabular}

Figura 3. Matriz de Entrincheiramento na Carreira e Satisfação na Carreira.

Nota. Fonte: Adaptado de Carson, K. D., Carson, P. P., Roe, C. W., \& Phillips, J. S. (1996). A career entrenchment model: theoretical development and empirical outcomes (pp. 274-278, pp. 282-284). Journal of Career Development, 22(4), 273286. doi: 10.1007/BF02259996

O exame desta matriz, construída pelos autores, nos permite explorar as relações entre comprometimento e entrincheiramento na carreira.

Em síntese, a matriz de entrincheiramento e satisfação na carreira (Figura 3) mostra o resultado do estudo teórico e empírico que Carson et al. (1996) realizaram acerca da relação do entrincheiramento com a satisfação na carreira, que resultou em quatro categorias de trabalhadores: o satisfeito imóvel, o aprisionado, o carreira voluntária e o trocar de carreira, cujas características estão discriminadas a seguir. 
O satisfeito imóvel (entrincheirado) e o voluntário (não entrincheirado), ambos satisfeitos com a carreira, apresentam o mais alto nível de comprometimento com a carreira, o mais alto nível de comprometimento organizacional afetivo, o mais alto nível de satisfação no trabalho, mais tempo de carreira e mais experiência educacional do que as outras duas categorias, que não são satisfeitos com a carreira (aprisionado e trocar de carreira).

O satisfeito imóvel (entrincheirado e satisfeito com a carreira) apresenta o nível mais alto de comprometimento com a carreira e mais baixo nível de intenção de deixar a carreira do que as outras três categorias (aprisionado, mudança de carreira e carreira voluntária).

O satisfeito imóvel e o aprisionado (ambos entrincheirados) mostram níveis mais elevados de compromisso organizacional instrumental (por causa de suas similaridades, ou seja, ambos são vínculos pelos side-bets), intenção mais baixa de deixar a carreira, e tempo no cargo/carreira mais longo do que aqueles com mais baixo entrincheiramento na carreira.

O trocar de carreira (não entrincheirado e não satisfeito com a carreira) apresenta o mais alto nível de intenção de deixar a carreira; o nível mais baixo de comprometimento com a carreira; o menor tempo na carreira e a menor experiência educacional.

Analisando o estudo de Carson et al. (1996), verifica-se, portanto, que o entrincheiramento na carreira independe do nível de comprometimento com a carreira. Ou seja, o entrincheiramento e o comprometimento na carreira são vínculos distintos (mas não são opostos) e não são dependentes. Por exemplo, o satisfeito imóvel, que é entrincheirado, é a categoria que apresenta o nível mais alto de comprometimento com a carreira, enquanto o trocar de carreira, que não é entrincheirado, apresenta o nível mais baixo de comprometimento com a carreira. Carson et al. (1996) também demonstram que ser entrincheirado ou não na carreira, independe do nível de comprometimento organizacional afetivo (o satisfeito imóvel, que é entrincheirado, e o voluntário, que não é entrincheirado, apresentam o mais alto nível de comprometimento organizacional afetivo). No Brasil, Rowe e Bastos (2008) verificaram que os dois vínculos com a carreira - comprometimento e entrincheiramento - são construtos distintos. Os achados de Rowe e Bastos (2008) revelam correlação significativa, baixa e negativa entre esses dois construtos.

Em síntese, o entrincheiramento na carreira independe do comprometimento com a carreira e do comprometimento organizacional afetivo. Entretanto, o entrincheiramento na carreira está relacionado com o comprometimento organizacional instrumental.

As questões suscitadas pela matriz desenvolvida por Carson et al. (1996) revelam a importância de estudar, simultaneamente, estes dois potenciais vínculos com a carreira, objetivo importante deste trabalho, ao se testar se os dois construtos têm impactos diferenciados sobre o desempenho docente.

\section{Procedimentos Metodológicos}

Para atingir maior contingente de docentes de várias unidades da Federação, de forma mais rápida e com baixo custo, optou-se por utilizar survey por e-mail. Para essa decisão considerou-se, também, a elevada escolaridade e familiaridade com a Internet desta categoria ocupacional, fatores que poderiam elevar a taxa de participação.

A pesquisa, em termos do seu delineamento metodológico, consistiu em estudo de corte transversal, de natureza quantitativa, envolvendo a busca de teste de um modelo explicativo, permitindo a análise da natureza e da dinâmica dos vínculos com a carreira e seu impacto no esforço instrucional. Sua natureza explicativa decorre da busca de tornar inteligível o fenômeno sob investigação, justificando os motivos e os fatores que contribuem para a sua ocorrência (Vergara, 2007). O que permite avançar-se na construção e teste de modelos explicativos gerais é o acúmulo de pesquisas sobre comprometimento, o que gerou ao longo de décadas um conjunto significativo de 
relações deste fenômeno com antecedentes e consequentes diversos. O estudo possui também uma natureza descritiva porque, busca explicitar as características de determinada população ou de determinado fenômeno, podendo também estabelecer correlações entre variáveis e definir sua natureza. Este estudo toma como unidade de análise o trabalhador, no caso, o docente de ensino superior.

\section{Instrumento de coleta de dados}

Coerente com o desenho de um survey, utilizou-se um questionário estruturado em quatro partes. Na primeira parte, foram solicitados dados sociodemográficos; na segunda parte, dados ocupacionais. Nesses dois segmentos iniciais foram incluídos itens como: idade, gênero, estado civil, última titulação, área de atuação, tempo de serviço, Estado, natureza da IES (pública ou privada), regime de trabalho (DE, tempo parcial, horista), e se ocupa cargo de chefia. No terceiro segmento, constava a escala do esforço instrucional, na qual o docente fez sua autoavaliação referente a suas características como docente em sala de aula. O quarto segmento foi formado com as escalas de vínculos com a carreira - comprometimento e entrincheiramento. Vale ressaltar que o presente artigo faz parte de um estudo mais abrangente.

Para mensurar as duas variáveis centrais da pesquisa - comprometimento e entrincheiramento na carreira - utilizaram-se os instrumentos propostos por Carson e Bedeian (1994) e Carson et. al. (1995). São duas escalas em formato Likert, com 12 itens que cobrem as três dimensões que integram cada um dos construtos. Foram realizadas análises fatoriais e calculados os indicadores de fidedignidade das escalas, por estarem sendo aplicadas a um grupo ocupacional específico, distinto daquele que embasou a validação inicial das escalas.

A estrutura fatorial da escala de entrincheiramento na carreira revelou-se igual à estrutura original. Utilizando-se o método dos componentes principais, extração dos fatores com eigenvalue maior que um e a rotação varimax, foram identificadas e interpretadas três dimensões, cada uma com quatro itens. A matriz de correlação entre os itens apresenta determinante de 0,003, KMO de 0,84 e teste de esfericidade de Bartlett, com significância de 0,000. Os três fatores da escala explicam 69,68\% da variância total. Quanto à confiabilidade da medida, obteve-se um alpha de Cronbach de 0,84, considerado por Hair, Anderson, Tatham e Black (2005) como índice elevado e satisfatório. Os alphas de Cronbach por fator se situam acima de 0,82 .

O mesmo procedimento foi utilizado para avaliar a estrutura fatorial e a qualidade psicométrica da escala de comprometimento com a carreira de Carson e Bedeian (1994). Da mesma forma, encontrou a mesma estrutura original com três dimensões, tendo-se perdido apenas um item. A matriz de correlação entre os itens apresenta determinante de 0,009, KMO de 0,78 e teste de esfericidade de Bartlett com significância de 0,000 . Os três fatores da escala explicam $67,36 \%$ da variância total.

Segundo Collins (2002), o desempenho é estudado verificando os produtos e resultados alcançados pelo indivíduo, bem como os processos envolvidos e o grau de esforço despendido por ele na consecução de suas atividades e responsabilidades. Essa segunda vertente foi a adotada no presente estudo, delimitando-se o esforço instrucional do docente como indicador de seu desempenho.

$\mathrm{Na}$ literatura não foi encontrada uma escala em que o docente do ensino superior autoavaliasse o seu esforço instrucional, fornecendo uma medida do grau de investimento e empenho pessoal do docente na sua atividade de ensino, envolvendo, por exemplo, aspectos de preparação de aulas; dinâmicas das aulas; relacionamento com os discentes e exigência de estudo dos discentes. Assim, adaptou-se a escala de avaliação do esforço instrucional do docente do ensino superior realizada pelo discente de autoria de Lopes, Vectore, Gomide, Marques e Martins (2001), transformando-a em escala de autoavaliação, modelo Likert de cinco pontos. Essa escala foi submetida a uma análise fatorial, que resultou em cinco fatores que explicam $60 \%$ da variância total. O fator 1 foi denominado técnico, e denota o empenho do docente em esclarecer o conteúdo mediante a exposição dos itens, a utilização de exemplos e ilustrações, o esforço para que os alunos adquiram conhecimentos e habilidades que facilitem a análise de questões referentes ao assunto da disciplina e a assuntos mais complexos. O 
fator 2 foi nomeado de proteção, e representa a preocupação com as dificuldades de cada aluno, a disposição em ajudá-los, ouvindo seus problemas e dando-lhes atenção individualizada. $\mathrm{O}$ fator $\mathbf{3}$ foi denominado de exigência, e denota a exigência de uma carga elevada de estudos e trabalhos, acarretando bastante empenho do aluno. $O$ fator 4, intitulado perfeccionismo, representa $o$ planejamento detalhado das disciplinas, a preparação cuidadosa e com antecedência de cada aula, esquematizando ordenadamente as atividades das aulas. Por último, o fator $\mathbf{5}$ foi denominado encorajamento e denota o encorajamento dos alunos a participarem das discussões em aula, expressando abertamente suas idéias.

\section{Procedimentos para coleta, tratamento e análise dos dados}

Foi realizado um teste piloto do instrumento e da página da Internet em que foi hospedado. Com pequenas alterações, o questionário foi disponibilizado para os participantes. A solicitação de que o docente do ensino superior participasse desta pesquisa foi realizada por e-mail explicativo dos seus fins acadêmicos, contendo o link do endereço da página da Internet hospedeira do questionário. Esta pesquisa foi divulgada em sites de relacionamentos e em diversas comunidades de docentes de IES de todo o Brasil. Do mesmo modo, ainda no ambiente acadêmico, foi encaminhada para sindicatos, reitorias, departamentos, coordenações e secretarias, solicitando sua divulgação, para repassar para os e-mails dos docentes. Foram rastreadas listas de e-mails de docentes por meio de um site de busca e na página da Capes. O referido convite para participar da pesquisa ainda solicitava que o próprio docente o encaminhasse para sua lista de docentes do ensino superior, ampliando a possibilidade de participação de outros docentes. Devido à amplitude desta pesquisa, não foi possível escolher aleatoriamente docentes para responder ao questionário. Portanto a amostra participante desta pesquisa não pode ser considerada como representativa da população. Nesse caso, considera-se a amostra não probabilística e não intencional.

$\mathrm{Na}$ etapa de análise, primeiramente os dados coletados foram transportados para o Statistical Package for Social Sciences (SPSS) versão 15.0; e em seguida, foram tratados conforme princípios definidos por Hair et al. (2005) e Malhotra (2006). Realizaram-se análises exploratórias dos dados (avaliação da normalidade, outliers, linearidade e multicolinearidade), análise da qualidade da mensuração das escalas (dimensionalidade, confiabilidade e validade convergente e discriminante das medidas); finalmente, houve a modelagem de equações estruturais, com o método de máxima verossimilhança.

\section{Participantes}

Do total de 635 docentes que responderam ao questionário eletrônico, obtiveram-se participantes de todas as regiões do Brasil e das diversas áreas do conhecimento. Esses docentes são de 201 IES - 65 públicas e 136 privadas. Entre os participantes, 49,6\% são do sexo masculino e 50,4\% do sexo feminino. A maioria (60\%) é casada; a idade média é de 43 anos e 50,7\% são doutores. 55,1\% trabalham em IES pública e 44,9\% em IES privada. Destaca-se que a maior participação por instituição foi da Universidade Federal da Bahia (UFBA), com 76 docentes, seguida pela Universidade Federal do Rio Grande do Norte (UFRN) com 48; a Universidade de Brasília (UNB) apresenta a terceira maior participação, com 26 docentes.

\section{Resultados e Discussão}

Em congruência com o objetivo central da presente investigação, os resultados são apresentados, iniciando-se com os dados descritivos das variáveis centrais: esforço instrucional e vínculos com a carreira; em seguida, apresentam-se os dados obtidos com o teste do modelo de equações estruturais, que buscou testar os possíveis efeitos dos diferentes vínculos com a carreira sobre o esforço instrucional do docente. 


\section{Dados descritivos das variáveis da pesquisa: comprometimento e entrincheiramento na carreira e esforço instrucional}

As três variáveis centrais da pesquisa constituem conceitos multidimensionais, o que permite caracterizá-las em escores das suas dimensões constituintes. Tais resultados encontram-se na Figura 4, diferenciando-se os dois contextos de trabalho dos docentes (IES públicas e IES privadas). Adicionalmente foi verificado o nível de significância das diferenças das médias entre os dois contextos. Tal comparação se apoia no pressuposto de que os dois contextos se diferenciam fortemente, quanto às perspectivas de carreira que abrem para o docente, quer em termos de atividades que configuram o seu papel, quer em termos de expectativas que abrem para o processo de qualificação continuada. Subjacente a tais diferenças encontra-se a questão da estabilidade que caracteriza o vínculo público, diferente do vínculo privado, e a possibilidade de desenvolvimento da pesquisa ou da produção de conhecimento científico, não limitando o exercício docente a ministrar aulas.

Verifica-se que os níveis de comprometimento com a carreira são bastante elevados, próximos ao extremo positivo da escala, resultado que fortalece a noção de que a escolha da docência é guiada fortemente por uma identificação ou vocação pessoal. Por outro lado, os níveis de entrincheiramento são apenas moderadamente positivos (ligeiramente abaixo do ponto 4 da escala), revelando que o docente não se sente aprisionado a uma carreira por não ter alternativas; ao contrário, o maior peso no escore geral de entrincheiramento vem do fator 'custos emocionais' que, uma vez mais, revela que a sensação de entrincheirar-se se deve ao apego emocional à atividade docente. Ou seja, o aprisionamento à carreira é decorrente, em maior grau, dos custos emocionais consequentes do abandono do que da falta de alternativas ou outros investimentos já feitos. Este resultado se revela congruente com o maior nível de comprometimento, mostrando que só a existência de um vínculo afetivo pode justificar o mais elevado custo emocional com a saída da carreira.

Diferente da expectativa, os dados constantes na Figura 4 revelam que a natureza da instituição não altera significativamente a intensidade dos vínculos do docente com a sua carreira, tanto no comprometimento com a carreira quanto no entrincheiramento na carreira. Tais resultados revelam que o vínculo com a carreira é algo construído pelo docente, independentemente do contexto de como ele se insere no trabalho, o que fortalece o entendimento de que a carreira, ou a ocupação, ou profissão, é um foco mais central na estrutura de vínculos que o trabalhador desenvolve com as múltiplas facetas do mundo do trabalho. 


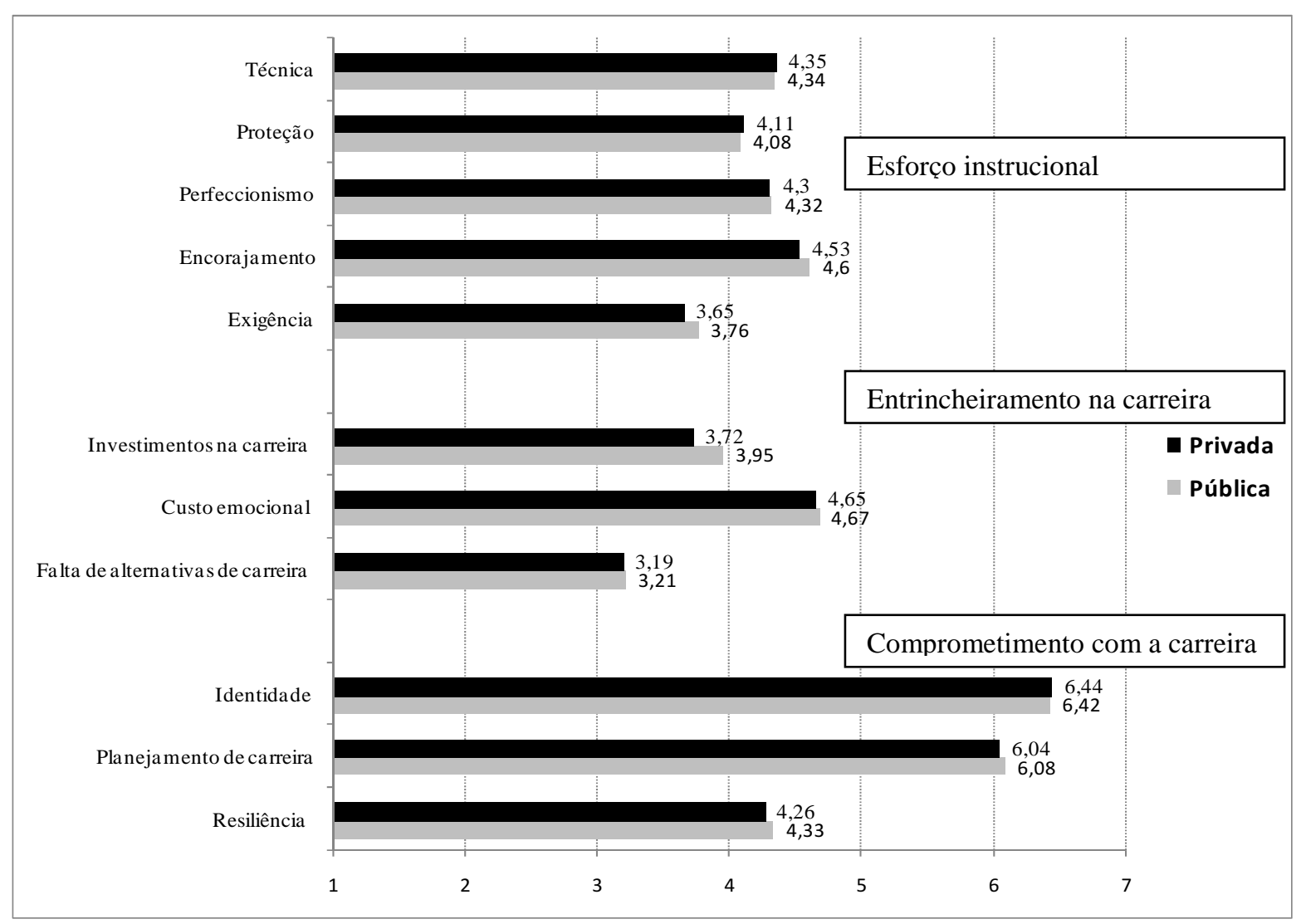

Figura 4. Médias das Dimensões do Esforço Instrucional e dos Vínculos com a Carreira. Fonte: Dados da pesquisa.

A terceira variável central da pesquisa, tomada como variável dependente, foi o esforço instrucional. Em uma escala de 5 pontos, o escore médio esteve apenas em um fator (exigência) abaixo do ponto 4. Para todos os demais fatores a avaliação pelo docente do seu esforço instrucional é elevada (proteção, perfeccionismo, técnica) ou muito elevada (encorajamento, que significa a preocupação dos docentes na motivação de seus alunos para que participem das aulas, expressando suas ideias). Quando se comparam os setores público e privado, a única diferença estatisticamente significativa está na dimensão exigência, sendo que o docente de IES pública exige um pouco mais de seus alunos do que seu colega de IES privada. Essa diferença é compreensível, pois geralmente o docente de IES pública tem mais liberdade e autonomia em seu trabalho, para exigir do aluno, do que o docente de determinadas IES privadas.

\section{A influência dos vínculos com a carreira no esforço instrucional}

A presente seção demonstra o modelo com as relações entre os vínculos com a carreira, formados pelo comprometimento e pelo entrincheiramento na carreira, com o esforço instrucional, utilizando-se a modelagem de equações estruturais. Na Figura 5, notam-se os pesos padronizados da regressão dos construtos independentes, bases dos vínculos com a carreira; nos construtos dependentes, notam-se os indicadores do esforço instrucional. As setas pontilhadas e em tonalidade cinza clara são caminhos ou relações que não apresentaram significância estatística no modelo.

Na Figura 5, observa-se que a dimensão identidade (comprometimento com a carreira), que expressa o comprometimento afetivo com a carreira, o apego emocional com a carreira influencia o esforço instrucional positivamente, com índices que variam de acordo com a dimensão do esforço instrucional: exigência 0,19 ; encorajamento 0,26 ; perfeccionismo 0,17 ; proteção 0,22 ; técnica 0,31 . Essa dimensão é a única que influencia todas as dimensões do esforço instrucional, o que comprova a forte relevância do comprometimento afetivo com a carreira, pelo seu impacto positivo no desempenho do trabalho. 
A relação positiva e moderada encontrada entre o comprometimento afetivo com a carreira (identidade) e o desempenho (esforço instrucional) está de acordo com Ellemers e Heuvel (1998), que sustentam não ser o comprometimento com a carreira um preditor confiável para o desempenho das pessoas, pela existência de diversos mediadores e moderadores desta relação.

A dimensão planejamento da carreira (comprometimento com a carreira) influencia positivamente três dimensões do esforço instrucional: exigência $(0,24)$, perfeccionismo $(0,24)$ e técnica $(0,17)$, conforme pode ser visualizado na Figura 5. Esses achados demonstram que toda a preparação do docente para o exercício da sua função, que tende a definir objetivos e metas para o seu desenvolvimento profissional, refletem positivamente no seu esforço instrucional. Vale ressaltar que o desenvolvimento da carreira do docente do ensino superior é um longo percurso, geralmente formado por mestrado, doutorado e até pós-doutorado, o que somam muitos anos de dedicação para o aprimoramento do conhecimento e para a qualificação profissional, tão demandada pelo mercado de trabalho.

A dimensão resiliência (comprometimento com a carreira) denota a relação custo-benefício percebida pelo docente referente à sua carreira, que analisa a relação entre os sacrifícios pessoais e os resultados ou retornos advindos dessa carreira. Essa dimensão influencia positivamente apenas duas dimensões do esforço instrucional: proteção $(0,12)$ e técnica $(0,12)$.

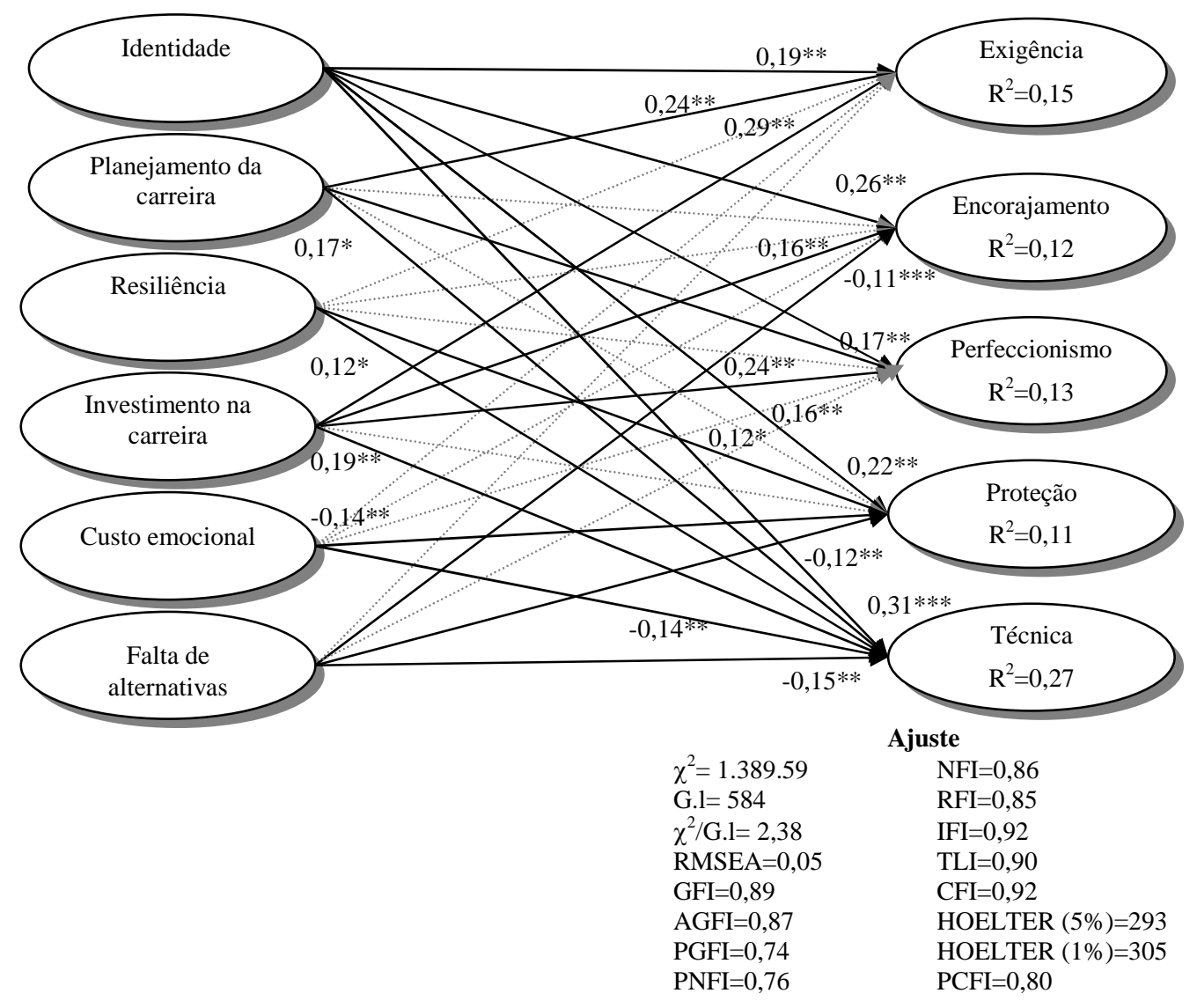

Figura 4. Modelo de Pesquisa: Vínculos com a Carreira e Esforço Instrucional.

Notas. *Significativo ao nível de $5 \%$ unicaudal $(\mathrm{p}<0,05)$; * Significativo ao nível de $1 \%$ unicaudal $(\mathrm{p}<0,01)$; ***Significativo ao nível de $0,1 \%$ unicaudal $(\mathrm{p}<0,001)$; $\mathrm{O} \mathrm{R}^{2}$ corresponde ao percentual de variância_explicada. Fonte: Dados da pesquisa.

De maneira geral, esse modelo expresso pela Figura 5 comprova a teoria que o comprometimento com a carreira leva a um maior desempenho (como, por exemplo, Carson \& Bedeian, 1994; Lee et al., 2000; Wallace, 1993). Verifica-se que as três dimensões do comprometimento com a carreira - identidade, planejamento da carreira e resiliência - influenciam, 
positivamente e significativamente, o desempenho do esforço instrucional do docente participante deste estudo.

Investimentos na carreira, segundo Carson et al. (1995), denota a percepção do sujeito referente aos seus investimentos financeiro, de tempo e conhecimentos específicos à sua carreira, que seriam perdidos no caso de uma mudança de carreira. A passagem do tempo traz consigo uma dimensão de investimentos passivos, que se acumulam, pois as habilidades são desenvolvidas e aperfeiçoadas no exercício diário da função. Tudo isso tende a fazer com que os indivíduos realmente ponderem os investimentos já realizados em sua carreira, ao analisar uma possível mudança de carreira.

Considerando-se o processo de entrincheiramento descrito por Carson e Carson (1997), o processo de investimento na carreira sucede à escolha de carreira e pode dar início ao entrincheiramento, pois no início da carreira, o indivíduo realiza investimentos financeiros e sustenta esforços para adquirir sucesso profissional. Esses investimentos continuam, quando a avaliação da congruência é positiva. Se estes investimentos forem altos, o indivíduo pode acreditar ter investido demais para mudar e, então, poderá racionalizar a permanência na carreira e se manter nela: pode tornar-se entrincheirado, caso não perceba novas alternativas de carreira.

No modelo expresso pela Figura 5, investimentos na carreira influenciam positivamente e significativamente as seguintes dimensões do esforço instrucional: exigência $(0,29)$; encorajamento $(0,16)$; perfeccionismo $(0,16)$ e técnica $(0,19)$. Ou seja, quanto mais o docente realiza investimentos na sua carreira, maior é o seu desempenho no esforço instrucional. Destaca-se que Carson et al. (1995) apontam que o trabalhador entrincheirado pode não representar problema para a organização. E acrescentam que as pessoas realizam maiores investimentos em carreiras que demandam mais conhecimento específico e correspondem, portanto, a níveis educacionais ou técnicos mais altos. Estes profissionais investem constantemente na manutenção de uma expertise específica, o que pode reduzir a probabilidade de mudança de carreira. E esse é o caso do docente do ensino superior; na amostra do presente estudo, esse investimento na carreira se reverte em aumento do esforço instrucional.

Custo emocional, que é uma dimensão de entrincheiramento na carreira, influencia negativamente duas dimensões do esforço instrucional: proteção e técnica. Esse resultado demonstra o seguinte: quanto mais o docente se vincula à sua carreira, por perceber uma perda afetiva e um impacto emocional, no caso de uma mudança de carreira, menor é o seu esforço instrucional. No caso do docente do ensino superior, o custo emocional se refere á perda do referencial social advindo da profissão, do status, do reconhecimento do meio acadêmico, assim como do âmbito familiar. Ou seja, como explicar para a sociedade que deixou de ser docente do ensino superior? Tarefa nada fácil e repleta de emoções, por ser uma categoria que se caracteriza pela alta exposição, que extrapola a sala de aula.

$\mathrm{Na}$ amostra deste estudo, a dimensão falta de alternativas de carreira, do vínculo entrincheiramento na carreira, influencia negativamente três dimensões do esforço instrucional do docente: encorajamento $(-0,11)$, proteção $(-0,12)$ e técnica $(-0,15)$, afetando de forma negativa $o$ desempenho desses docentes, de acordo com a apresentação da Figura 5. Os resultados demonstram que quanto mais o docente nota maior limitação de alternativas em caso de mudança de carreira, menor é o seu desempenho. Segundo Carson e Carson (1997), a falta de alternativas de carreira é a última fase do processo de entrincheiramento, que ocorre após os investimentos e os custos emocionais, e é o aspecto mais característico do entrincheiramento, porque reduz, de fato, a mobilidade de carreira.

$\mathrm{Na}$ análise deste modelo, que verifica as explicações do esforço instrucional pelos vínculos com a carreira, nota-se que a dimensão do esforço instrucional, denominada técnica, se destaca por ser a dimensão que é mais explicada pelos vínculos com a carreira.

Em síntese, o conjunto de dados apresentados na Figura 5 revela a importância dos vínculos com a carreira na explicação do esforço instrucional do docente do ensino superior. Esses resultados se coadunam com a análise clássica de Campbell (1990), que identificou o comprometimento como um 
dos 30 principais preditores do desempenho no trabalho, que podem explicar importante parcela significativa de desempenho.

Uma curiosidade que surge, após verificar as influências dos vínculos com a carreira no esforço instrucional, consiste em saber se há diferenças nos modelos explicativos do desempenho entre docentes de instituições públicas e privadas, devido às suas características peculiares.

\section{Comparando as influências dos vínculos com a carreira no esforço instrucional entre docentes de IES públicas e privadas}

Com a finalidade de explorar possíveis diferenças entre os contextos público e privado do ensino superior, foi utilizada a modelagem de equações estruturais com uma análise multigrupos. Esse procedimento consiste em uma ferramenta adequada para comparar modelos com populações supostamente distintas, segundo Tabachnick e Fidell (2001).

No modelo demonstrado na Tabela 2, apresentam-se os coeficientes de impacto das diferentes dimensões dos vínculos com a carreira sobre as dimensões de esforço instrucional entre IES públicas e privadas. De forma geral, existem especificidades na influência dos vínculos sobre o esforço instrucional, quando se consideram os docentes que atuam em diferentes contextos. A seguir, tais peculiaridades são apresentadas detalhadamente.

Apresenta-se a análise de um olhar nas dimensões de comprometimento com a carreira, neste modelo multigrupos (Tabela 2). Em comum, destaca-se a influência positiva e significativa da dimensão identidade (comprometimento com a carreira), demonstrando que quanto maior é a importância da atividade profissional para o autoconceito do docente, maior é o seu esforço instrucional, independentemente do tipo do esforço instrucional e do tipo de IES que este docente esteja vinculado: pública ou privada.

Curiosamente, resiliência (comprometimento com a carreira) não influencia o esforço instrucional do docente de IES pública, conforme demonstra a Tabela 2; enquanto no docente de IES privada, resiliência ora não exerce influência significativa (nas dimensões exigência e perfeccionismo), ora exerce influência significativa e positiva (nas dimensões encorajamento, proteção e técnica). Portanto, para o esforço instrucional encorajamento, proteção e técnica de docentes vinculados à IES privada, sua capacidade para transpor e enfrentar dificuldades, frustrações e estresses oriundos de seu exercício profissional, influencia positivamente seu esforço instrucional. Exemplos de problemas profissionais do docente de IES privada são mencionados a seguir. O relacionamento com determinados alunos, principalmente aqueles que não estão motivados a aprender. A gestão da IES, quando apresenta uma preocupação exagerada em 'agradar seu cliente', fato este que acaba por limitar a autonomia do trabalho do docente. O vínculo de trabalho horista, a falta de estabilidade e a baixa remuneração, que levam o docente a se vincular com várias IES, e/ou a atuar no mercado de trabalho, exercendo outras funções, extra-acadêmicas. E limita seu tempo de dedicação para o esforço instrucional, por um lado; por outro lado, sofre pressão pelo seu bom desempenho. A cobrança do desempenho do docente ocorre de múltiplas fontes: do próprio docente, dos discentes, da IES e dos próprios colegas.

A resiliência do docente é a sua capacidade de superar todos os problemas profissionais e ainda perceber que continuar atuando na docência do ensino superior é recompensador. Ou seja, supera todas as adversidades profissionais pelo ideal de oportunizar e facilitar o desenvolvimento intelectual do discente e, consequentemente, obter reconhecimento profissional.

Acerca da falta de estabilidade no trabalho nas organizações contemporâneas, que também afetam o docente, Bauman (1999, p. 113) ressalta:

os empregos surgem e somem assim que aparecem, são fragmentados e eliminados sem aviso prévio, como as mudanças nas regras do jogo de contratação e demissão - e pouco podem fazer os empregados, ou os que buscam emprego para parar essa gangorra. 
As IES públicas oferecem mais oportunidades para que o docente planeje sua carreira, ao oferecer estabilidade e, principalmente, ao apoiar e investir na capacitação profissional em cursos de pós-graduação stricto sensu. Já nas IES privadas, esse apoio e investimento são mais difíceis, culminando com o fato de que a maioria dos seus docentes planeja sua carreira sozinho, sem o apoio da sua instituição. Essa realidade parece ter refletido nos resultados expostos a seguir. Planejamento de carreira (comprometimento com a carreira) influencia negativamente apenas a dimensão encorajamento (esforço instrucional) no grupo de IES privadas. Entretanto, nos docentes de IES públicas, o planejamento de carreira somente não influencia positivamente o esforço instrucional proteção. Por conseguinte, de maneira geral, podemos afirmar que nas IES públicas (com exceção do esforço instrucional proteção), quanto mais o docente planeja sua carreira, determinando suas necessidades de desenvolvimento e estabelecendo metas de carreira, maior é o seu esforço instrucional. E o inverso ocorre com o esforço instrucional encorajamento no docente de IES privadas: quanto mais ele planeja sua carreira, menos ele encoraja seus alunos a participar das discussões em aula, expressando abertamente suas ideias.

Interessante notar que no modelo da Figura 5 (que expressa o modelo estrutural entre os vínculos com a carreira e o esforço instrucional), a dimensão planejamento de carreira não tem poder explicativo no esforço instrucional, denominado encorajamento. Entretanto, nesta análise multigrupo expresso na Tabela 2, verifica-se que a dimensão planejamento de carreira influencia o esforço instrucional encorajamento; porém, nas IES públicas, essa influência é positiva, enquanto, nas IES privadas, essa influência é negativa. Ressalta-se que, por serem influências contrárias, na análise conjunta entre IES públicas e privadas demonstrada na Figura 5, elas não são significativas, pois se anulam, com uma positiva (IES públicas) e outra negativa (IES privadas).

Tabela 2

Modelo dos Vínculos com a Carreira e Esforço Instrucional: Comparação por Grupo de Docentes - IES Públicas e Privadas

\begin{tabular}{|c|c|c|c|}
\hline \multicolumn{2}{|c|}{ CONSTRUTOS } & \multicolumn{2}{|c|}{ GRUPO DE IES } \\
\hline $\begin{array}{l}\text { INDEPENDENTES: } \\
\text { Vínculos com a Carreira }\end{array}$ & $\begin{array}{l}\text { DEPENDENTES: } \\
\text { Esforço Instrucional }\end{array}$ & PÚBLICAS & PRIVADAS \\
\hline \multicolumn{4}{|l|}{ Entrincheiramento na carreira } \\
\hline Investimentos na carreira & \multirow{3}{*}{$\begin{array}{c}\text { DOCENTE } \\
\text { ENCORAJAMENTO }\end{array}$} & $-0,12$ & $0,34 * * *$ \\
\hline Custos emocionais & & 0,07 & $-0,25 * *$ \\
\hline Falta de alternativas de carreira & & $-0,04$ & $-0,18^{*}$ \\
\hline Comprometimento com a carreira & \multirow{4}{*}{$\begin{array}{l}\mathrm{R}^{2} \text { públicas }=0,15 \\
\mathrm{R}^{2} \text { privadas }=0,18\end{array}$} & & \\
\hline Resiliência & & $-0,06$ & $0,23 * *$ \\
\hline Planejamento de carreira & & $0,17 *$ & $-0,26 *$ \\
\hline Identidade & & $0,26 * * *$ & $0,27 *$ \\
\hline \multicolumn{4}{|l|}{ Entrincheiramento na carreira } \\
\hline Investimentos na carreira & \multirow{3}{*}{$\begin{array}{c}\text { DOCENTE } \\
\text { EXIGÊNCIA }\end{array}$} & 0,02 & $0,47^{* * *}$ \\
\hline Custos emocionais & & $-0,02$ & $-0,18$ \\
\hline Falta de alternativas de carreira & & $-0,16^{*}$ & $-0,02$ \\
\hline Comprometimento com a carreira & \multirow{4}{*}{$\begin{array}{l}\mathrm{R}^{2} \text { públicas }=0,13 \\
\mathrm{R}^{2} \text { privadas }=0,21\end{array}$} & & \\
\hline Resiliência & & 0,01 & 0,17 \\
\hline Planejamento de carreira & & $0,20 * *$ & 0,12 \\
\hline Identidade & & $0,18^{*}$ & $0,20^{*}$ \\
\hline
\end{tabular}


Tabela 2 (continuação)

\begin{tabular}{|c|c|c|c|}
\hline CONSTRUTOS & GRUPO DE IES & & \\
\hline $\begin{array}{l}\text { INDEPENDENTES: } \\
\text { Vínculos com a Carreira }\end{array}$ & $\begin{array}{l}\text { DEPENDENTES: } \\
\text { Esforço Instrucional }\end{array}$ & PÚBLICAS & PRIVADAS \\
\hline \multicolumn{4}{|l|}{ Entrincheiramento na carreira } \\
\hline Investimentos na carreira & \multirow{3}{*}{$\begin{array}{c}\text { DOCENTE } \\
\text { PROTEÇÃOO }\end{array}$} & $-0,14$ & $0,29 * * *$ \\
\hline Custos emocionais & & $-0,02$ & $-0,15$ \\
\hline Falta de alternativas de carreira & & $-0,09$ & $-0,15$ \\
\hline Comprometimento com a carreira & \multirow{4}{*}{$\begin{array}{l}\mathrm{R}^{2} \text { públicas }=0,13 \\
\mathrm{R}^{2} \text { privadas }=0,13\end{array}$} & & \\
\hline Resiliência & & $-0,01$ & $0,24 * *$ \\
\hline Planejamento de carreira & & 0,12 & $-0,04$ \\
\hline Identidade & & $0,24 * * *$ & $0,18^{*}$ \\
\hline \multicolumn{4}{|l|}{ Entrincheiramento na carreira } \\
\hline Investimentos na carreira & \multirow{3}{*}{$\begin{array}{c}\text { DOCENTE } \\
\text { PERFECCIONISMO }\end{array}$} & $-0,17 *$ & $0,43^{* * *}$ \\
\hline Custos emocionais & & 0,04 & $-0,26^{* *}$ \\
\hline Falta de alternativas de carreira & & $-0,02$ & $-0,16^{*}$ \\
\hline Comprometimento com a carreira & \multirow{4}{*}{$\begin{array}{l}\mathrm{R}^{2} \text { públicas }=0,14 \\
\mathrm{R}^{2} \text { privadas }=0,22\end{array}$} & & \\
\hline Resiliência & & $-0,02$ & 0,07 \\
\hline Planejamento de carreira & & $0,27 * * *$ & 0,17 \\
\hline Identidade & & $0,12 * *$ & $0,24 *$ \\
\hline \multicolumn{4}{|l|}{ Entrincheiramento na carreira } \\
\hline Investimentos na carreira & \multirow{3}{*}{$\begin{array}{l}\text { DOCENTE } \\
\text { TÉCNICA }\end{array}$} & $-0,11$ & $0,44^{* * *}$ \\
\hline Custos emocionais & & 0,02 & $-0,26 * *$ \\
\hline Falta de alternativas de carreira & & $-0,16^{* *}$ & $-0,13$ \\
\hline Comprometimento com a carreira & \multirow{4}{*}{$\begin{array}{l}\mathrm{R}^{2} \text { públicas }=0,40 \\
\mathrm{R}^{2} \text { privadas }=0,26\end{array}$} & & \\
\hline Resiliência & & 0.00 & $0,25 * * *$ \\
\hline Planejamento de carreira & & $0,29 * * *$ & 0,17 \\
\hline Identidade & & $0,36^{* * *}$ & $0,21^{*}$ \\
\hline
\end{tabular}

Notas. *Significativo ao nível de $5 \%$ unicaudal $(\mathrm{p}<0,05)$; * Significativo ao nível de $1 \%$ unicaudal $(\mathrm{p}<0,01)$; ***Significativo ao nível de $0,1 \%$ unicaudal $(\mathrm{p}<0,001) ; \mathrm{R}^{2}$ - percentual de variância explicada.

Fonte: Dados da pesquisa.

Destaca-se uma apreciação das dimensões do entrincheiramento na carreira, do modelo de vínculos com a carreira e esforço instrucional (Tabela 2). Observa-se que a dimensão falta de alternativas de carreira (entrincheiramento na carreira) exerce influência significativa e negativa, demonstrando que quanto mais o docente percebe a falta de disponibilidade e de diversidade de opções de carreira, no caso de uma transição, menor é o seu esforço instrucional (IES públicas: esforço instrucional exigência e técnica; IES privadas: encorajamento e perfeccionismo).

Custos emocionais (entrincheiramento na carreira) não são explicativos de nenhuma dimensão do esforço instrucional entre docentes de IES pública. Quanto aos docentes de IES privadas, ou não apresenta significância (esforço instrucional exigência e proteção), ou é significativo e negativo (esforço instrucional encorajamento, perfeccionismo e técnica). Esses dados revelam que quanto mais o docente de IES privada nota que lhe parece emocionalmente difícil mudar de carreira, menor é o seu esforço instrucional nas dimensões encorajamento, perfeccionismo e técnica. 
A dimensão investimentos na carreira (entrincheiramento na carreira) entre docentes de IES pública somente exerce influência no esforço instrucional perfeccionismo, sendo esta influência negativa. Entre docentes de IES privada, esta dimensão explica positivamente parcela considerável de todos os tipos de esforço instrucional. Esse dado demonstra que quanto mais o docente de IES privada se dedica em prol do desenvolvimento de sua carreira, com investimentos financeiro e temporal, maior é o seu esforço instrucional.

Em suma, quanto à diferença do impacto das dimensões dos vínculos com a carreira no esforço instrucional, entre IES pública e privada, destaca-se a dimensão resiliência (comprometimento com a carreira), que não influencia o esforço instrucional do docente de IES pública, enquanto influencia o esforço do docente de IES privada, nas dimensões encorajamento, proteção e técnica. A dimensão planejamento de carreira (comprometimento com a carreira) influencia positivamente o esforço instrucional do docente de IES pública (com exceção da dimensão proteção), enquanto não influencia o esforço instrucional do docente de IES privada (com exceção da dimensão encorajamento, cuja influência é negativa). Vale destacar que a dimensão custos emocionais (entrincheiramento na carreira) não influencia o esforço instrucional do docente de IES pública, enquanto influencia negativamente o esforço instrucional do docente de IES privada, nas dimensões encorajamento, perfeccionismo e técnica. Ressalta-se que a dimensão investimentos na carreira (entrincheiramento na carreira) influencia positivamente o esforço instrucional do docente de IES privada, enquanto não exerce influência no esforço do docente de IES pública (com exceção da dimensão perfeccionismo, que sofre influência negativa). A comparação entre os contextos público e privado também apresenta similaridade, como a influência da dimensão afetiva (identidade) do comprometimento com a carreira, que influencia todas as dimensões do esforço instrucional, nas IES públicas e privadas. De uma maneira geral, observa-se que as dimensões do entrincheiramento influenciam mais o esforço instrucional do docente de IES privada do que do docente de IES pública.

\section{Considerações Finais}

No Brasil, o ensino superior tem-se expandido consideravelmente nos últimos anos. Inserido em um quadro geral de flexibilização e precarização do trabalho, na maioria das IES privadas prevalece o vínculo horista para grande parte de seus docentes. Com isto, os docentes são levados a buscar conciliar o trabalho em duas ou mais instituições, ou o trabalho docente com uma carreira técnica. A incerteza de sua permanência na IES também faz parte de sua rotina de trabalho. Por sua vez, o docente de IES pública, para complementar sua remuneração, necessita de bolsa de produtividade de pesquisa e precisa dedicar-se a atividades de extensão. Docentes de IES públicas e privadas possuem contextos de trabalho bastante diferentes; entretanto, ambos os contextos possuem particularidades que fragilizam o seu comprometimento com a organização e que pode levá-lo a privilegiar a sua carreira. No entanto, este vínculo com a carreira pode ser de comprometimento ou de entrincheiramento, fenômenos psicossociais assaz diferenciados quanto a seus impactos possíveis no desempenho. Explorar, comparar e avaliar os impactos destes dois vínculos sobre o desempenho do docente constituiu o objetivo central do presente estudo.

Tal objetivo justifica-se, adicionalmente, por ser a influência dos vínculos de comprometimento com a carreira e entrincheiramento na carreira, temas ainda pouco explorados, especialmente no cenário nacional. Na realidade, esta relação é um dos pontos mais consensuais da agenda internacional de pesquisa sobre comprometimento no trabalho, como algo que deve merecer esforços dos pesquisadores. Muito se conhece sobre os antecedentes do comprometimento e pouco ainda se sabe, com evidências científicas, sobre os seus impactos no trabalho. Ampliar os estudos sobre o trabalho docente, suas condições e determinantes da qualidade do seu desempenho ganha relevância ainda maior, quando se considera a importante função social deste grupo de trabalhadores.

Mais especificamente, este trabalho permitiu identificar que dimensões, tanto do comprometimento quanto do entrincheiramento, melhor explicam níveis diferentes de esforço 
instrucional do docente. Nos modelos obtidos a partir dos resultados da pesquisa, verificou-se que a dimensão identidade do comprometimento influencia positivamente o esforço instrucional. Essa dimensão afetiva é a única que exerce influência em todas as dimensões do esforço instrucional, nos contextos público e privado. De maneira geral, os dados desta pesquisa comprovam a teoria de que o comprometimento com a carreira leva a um maior desempenho. Verifica-se que as três dimensões do comprometimento com a carreira - identidade, planejamento de carreira e resiliência - influenciam positivamente o esforço instrucional. Quanto ao entrincheiramento na carreira, vale destacar que a dimensão investimentos na carreira influencia positivamente o esforço instrucional, demonstrando que quanto mais o docente investe tempo e dinheiro à capacitação profissional, a tendência é o aumento do seu esforço instrucional. Ou seja, os investimentos acumulados em uma carreira que seriam perdidos, ou menos aproveitados, com uma mudança de carreira, no caso do docente do ensino superior participante deste estudo, se revertem em maior desempenho. Comparando-se os diferentes resultados dos impactos destes dois tipos de vínculos sobre o esforço instrucional do docente, a pesquisa contribui de forma importante para diferenciar estes dois vínculos, fortalecendo as considerações teóricas de que a permanência numa carreira não é um indicador apenas de comprometimento. Pelo contrário, a permanência pode dever-se ao entrincheiramento, ou ao sentir-se aprisionado pelos investimentos feitos e custos envolvidos com novo percurso profissional. Tal resultado tem, além de tudo, importante impacto prático para a gestão de carreiras, até mesmo na docente.

Acrescente-se que a presente pesquisa também comparou os contextos em que se inserem os docentes: se em IES públicas ou privadas. Vínculos empregatícios que asseguram maior estabilidade no trabalho e circunstâncias para o desenvolvimento de atividades de pesquisa e extensão caracterizam a maioria das IES públicas, em oposição às instituições privadas. Tais vínculos podem ser fator tanto de comprometimento quanto de entrincheiramento, a depender de como fatores pessoais e organizacionais interagem nas avaliações feitas pelos docentes. Os resultados obtidos indicaram que o esforço instrucional é apenas parcialmente explicado pela natureza e intensidade dos vínculos com a carreira. Algumas diferenças foram encontradas entre dimensões dos vínculos e dimensões do esforço instrucional, sem contudo configurar situações radicalmente diferentes, quanto à variável critério do estudo. Outros fatores devem ser considerados como antecedentes em novos estudos. Além disso, o desempenho no trabalho depende de diversos fatores situacionais e individuais.

Os dados apresentados, aqui, não revelaram fortes relações entre os vínculos com a carreira e o esforço instrucional; entretanto essas relações são significativas, apontando a necessidade de mais pesquisas. Sugere-se que modelos explicativos mais amplos, que considerem outras variáveis além dos vínculos com a carreira, devem ser desenvolvidos e testados em estudos posteriores.

Em síntese, o presente trabalho evidencia a relevância dos vínculos com a carreira do docente do ensino superior, no contexto nacional, para o seu desempenho docente, corroborando a importância dos vínculos com o trabalho para o desempenho do trabalhador, pressuposto este com poucas evidências empíricas, até então.

Como qualquer trabalho, a presente pesquisa apresenta alguns limites que devem ser considerados na avaliação do alcance dos seus resultados. O primeiro deles é que a amostra estudada não tem garantia de aleatoriedade nem de representatividade de todos os docentes do ensino superior no Brasil, em suas diversas características. Embora a amostra atingida seja ampla e suficiente para as análises realizadas e tenha, até mesmo, abrangência nacional, certamente, novos estudos que agreguem mais docentes, de diferentes contextos institucionais, podem contribuir para fortalecer ou rever os resultados aqui obtidos. Vale ressaltar que, por ser o primeiro estudo que estabelece a relação entre os vínculos com a carreira e o esforço instrucional do docente, fica-se sem o amparo de uma produção científica prévia que sirva para oferecer uma base de confronto dos dados obtidos. Neste sentido, as interpretações se baseiam mais na teoria que embasa os dois construtos do que em resultados empíricos prévios.

A título de contribuição para pesquisas futuras, sugerem-se estudos que incluam variáveis mediadoras entre os vínculos com a carreira e o desempenho, como por exemplo, o tempo no cargo e na organização e outras características da esfera extratrabalho, como filhos e casamento. Outra 
sugestão para estudo adicional dos vínculos com a carreira do docente do ensino superior é a segmentação da atuação desse docente, que pode ser graduação, lato sensu, stricto sensu, extensão. Certamente, variáveis do contexto específico de inserção do docente e dados de sua trajetória profissional, incluindo o processo de escolha da profissão, poderão agregar informações importantes para a compreensão dos impactos dos vínculos com o desempenho. A inclusão de variáveis moderadoras deve conduzir a modelos mais complexos e sofisticados, certamente mais apropriados para captar as relações existentes entre estes complexos e multideterminados fenômenos.

\section{Artigo recebido em 16.11.2010. Aprovado em 12.08.2011.}

\section{Referências}

Aryee, S., \& Tan, K. (1992). Antecedents and outcomes of career commitment. Journal of Vocational Behavior, 40(3), 288-305. doi: 10.1016/0001-8791(92)90052-2

Bastos, A. V. B. (1994). Múltiplos comprometimentos no trabalho: a estrutura dos vínculos do trabalhador coma organização, a carreira e o sindicato (Tese de doutorado). Universidade de Brasília, Brasília, DF, Brasil.

Bauman, Z. (1999). Globalização: as consequências humanas. Rio de Janeiro: Jorge Zahar.

Blau, G. (1985). The measurement and prediction of career commitment. Journal of Occupational Psychology, 58(4), 277-288. doi: 10.1111/j.2044-8325.1985.tb00201.x

Blau, G. (2001). On assessing the construct validity of two multidimensional constructs: occupational commitment and occupational entrenchment. Human Resource Management Review, 11(3), 279-298. doi: 10.1016/S1053-4822(00)00052-8

Campbell, J. P. (1990). Modeling the performance prediction problem in industrial and organizational psychology. In M. D. Dunnette \& L. M. Hough (Eds.), Handbook of industrial and organizational psychology (pp. 687-732). Palo Alto, CA: Consulting Psychologists Press.

Carson, K.D., \& Bedeian, A. (1994). Career commitment: construction of a measure and examination of its psychometric properties. Journal of Vocational Behavior, 44(3), 237-262. doi: 10.1006/jvbe.1994.1017

Carson, K. D., \& Carson, P. P. (1997). Career entrenchment: a quiet march toward occupational death? Academy Of Management Executive, 11(1), 62-75.

Carson, K. D., Carson, P., \& Bedeian, A. (1995). Development and construct validation of a career entrenchment measure. Journal of Occupational and Organizational Psychology, 68(4), 301320. doi: 10.1111/j.2044-8325.1995.tb00589.x

Carson, K. D., Carson, P. P., Roe, C. W., \& Phillips, J. S. (1996). A career entrenchment model: theoretical development and empirical outcomes. Journal of Career Development, 22(4), 273286. doi: 10.1007/BF02259996

Cohen, A. (2003). Multiple commitments in workplaces: an integrative approach. Mahwah, NJ: Lawrence Erlbaum Associates.

Collins, D. B. (2002). Performance-level evaluation methods used in management development studies from 1986 to 2000. Human Resource Development Review, 1(1), 91-110. doi: $10.1177 / 1534484302011005$ 
Ellemers, N., \& Heuvel, D. van den (1998). Career-oriented versus team-oriented commitment and behavior at work. Journal of Applied Psychology, 83(5), 717-730. doi: 10.1037//00219010.83.5.717

Goulet, L., \& Singh, P. (2002). Career commitment: a reexamination and an extension. Journal of Vocational Behavior, 61(1), 73-91. doi: 10.1006/jvbe.2001.1844

Hair, J. F., Jr., Anderson, R. E., Tatham, R. L., \& Black, W. C. (2005). Análise multivariada de dados (5a ed.). Porto Alegre: Bookman.

Kilimnik, Z., Castilho, I., \& Sant'Anna, A. (2006). Carreiras em transformação e seus paradoxais reflexos nos indivíduos: metáforas de carreira e de competências. Comportamento Organizacional e Gestão, 12(2), 257-280.

Lee, K., Carswell, J., \& Allen, N. (2000). A meta-analytic review of occupational commitment: relations with person and work-related variables. Journal of Applied Psychology, 85(5), 799811. doi: 10.1037/0021-9010.85.5.799

London, M. (1983). Toward a theory of career motivation. Academy of Management Review, 8(4), 620-630. doi: $10.2307 / 258263$

Lopes, E. J., Vectore, C., Gomide, S., Marques, S. L., \& Martins, M. C. F. (2001, maio). Características psicométricas da escala de avaliação do planejamento e execução do trabalho do professor. Anais do Congresso Norte Nordeste de Psicologia, Salvador, BA, Brasil, 2.

Malhotra, N. (2006). Pesquisa de marketing: uma orientação aplicada (4a ed.). Porto Alegre: Bookman.

Rowe, D. E. O., \& Bastos, A. V. B. (2008, setembro). Comprometimento ou entrincheiramento na carreira? Um estudo entre docentes do ensino superior. Anais do Encontro Nacional da Associação Nacional de Pós-Graduação e Pesquisa em Administração, Rio de Janeiro, RJ, Brasil, 32.

Scheible, A. C. F., Bastos, A. V. B., \& Rodrigues, A. C. A. de (2007, setembro). Comprometimento e entrincheiramento: integrar ou reconstruir? Uma exploração das relações entre estes construtos à luz do desempenho. Anais do Encontro Nacional da Associação Nacional de Pós-Graduação e Pesquisa em Administração, Rio de Janeiro, RJ, Brasil, 31.

Somech, A., \& Bogler, R. (2002). Antecedents and consequences of teacher organizational and professional commitment. Educational Administration Quarterly, 38(4), 555-577. doi: $10.1177 / 001316102237672$

Sonnentag, F., \& Frese, M. (2002). Performance concepts and performance theory. In S. Sonnentag (Ed.), Psychological Management of Individual Performance (pp. 3-25). Great Britain: John Wiley \& Sons, Ltd.

Tabachnick, B. G., \& Fidell, L. S. (2001). Using multivariate statistics (3a ed.). New York: HarperCollins.

Vergara, S. C. (2007). Projetos e relatórios de pesquisa em administração (8a ed.). São Paulo: Atlas.

Wallace, J. E. (1993). Professional and organizational commitment: compatible or incompatible? Journal of Vocational Behavior, 42(3), 333-349. doi: 10.1006/jvbe.1993.1023 